\title{
Soy Flour Fortification of Whole Wheat Meal Possessed Low Glycemic Index and Glycemic Load and Reduced Cardiovascular Disease Risk Factors
}

\author{
Sunday Adeola Emaleku*, Godsent Oluwakemi Emaleku and Olusola D Omueti \\ Department of Biochemistry, Adekunle Ajasin University, Akungba Akoko, Ondo State, Nigeria
}

"Corresponding author: Sunday Adeola Emaleku, Department of Biochemistry, Adekunle Ajasin University, P.M.B. 01, Akungba Akoko, Ondo State, Nigeria, Tel: 2348034219631; E-mail: crownsage@yahoo.com; sunday.emaleku@aaua.edu.ng

Received: February 27, 2018; Accepted: March 21, 2018; Published: March 23, 2018

Copyright: (C) 2018 Emaleku SA, et al. This is an open-access article distributed under the terms of the creative commons attribution license, which permits unrestricted use, distribution, and reproduction in any medium, provided the original author and source are credited.

\section{Abstract}

Objectives: Foods with high glycemic index $(\mathrm{Gl})$ and/or glycemic load $(\mathrm{GL})$ have been reported to have etiology in the incidence and prevalence of diabetes mellitus (DM) and its related chronic metabolic diseases like cardiovascular diseases (CVDs) etc. facing the globe today. High GI in particular has been found to have positive association with hyperglycemia, DM and CVDs such as hyperlipidemia, hypercholesterolemia, atherosclerosis etc. Therefore, the aim of this study is to investigate soy flour fortified whole wheat meal consumed with Crassocephalum biafrae (Worowo) vegetable soup's dietary glycemic index and glycemic load, and its effects on lipid profiles of the test human subjects.

Methods: Eighteen human subjects were divided into two equal groups (control and test groups) of nine participants each. After $12 \mathrm{~h}$ of overnight fasting, the control group were fed D-glucose (DG) on the first day of the experiment, while the test group were fed whole wheat meal cum Crassocephalum biafrae soup (WWMCBS) and soy flour fortified whole wheat meal cum Crassocephalum biafrae soup (SFFWWMCBS) on the first and second day respectively. Fasting blood sugar and random blood sugar levels were determined at 30 min interval for $2 \mathrm{~h}$ using glucometer and blood samples were collected $5 \mathrm{~h}$ after meal for lipid profiles assay.

Results: Findings showed that; SFFWWMCBS had GI and GL of $28.00 \%$ and 14.00 respectively that are nonsignificantly lesser than that of WWMCBS $(42.67 \%$ and 21.34$)$ respectively, and its consumption resulted in nonsignificant reductions in total cholesterol $(140.00 \mathrm{mg} / \mathrm{dl}-139.33 \mathrm{mg} / \mathrm{dl})$, triglyceride $(84.00 \mathrm{mg} / \mathrm{dl}-78.33 \mathrm{mg} / \mathrm{dl})$, low density lipoprotein cholesterol $(60.67 \mathrm{mg} / \mathrm{dl}-57.67 \mathrm{mg} / \mathrm{dl})$, but slight increase in high density lipoprotein cholesterol $(62.33 \mathrm{mg} / \mathrm{dl}-65.00 \mathrm{mg} / \mathrm{dl})$ in test human subjects at $(\mathrm{p}<0.05)$.

Conclusion: Conclusively, SFFWWMCBS had lower GI and GL than WWMCBS, and have the potentials to reduce CVDs risk factors, since it decreased cholesterol, triglyceride and LDL-C, but improved HDL-C.

Keywords: Cardiovascular disease; Cardiovascular disease risk factors; Diabetes mellitus; Glycemic index; Glycemic load; Hyperglycemia

\section{Introduction}

Non-communicable diseases such as diabetes mellitus (DM), cardiovascular diseases (CVDs), cancer etc. were reported by World Health Organization in 2011 to be responsible for $63 \%$ of all deaths worldwide. In particular, deaths from DM and CVDs account for more than $50 \%$ of the global mortality, resulting in over 17 or 18 million deaths annually [1].

Hyperglycemia (a condition of elevated blood glucose level) is a hallmark of DM and is also reported to be a major risk factor for CVDs [2] due to its effects on lipid profiles and has its etiology in glycemic index (GI) and/or glycemic load (GL) of foods in addition to other causes. Thus, high GI and GL foods are key factors or parameters in the pathogenesis of hyperglycemia, DM and invariably CVDs.

The concept of GI was introduced more than two decades ago to facilitate glycemic control in patients with DM, and is an indicator ranking carbohydrate foods according to their effects on the body's postprandial glycemic response [3], while GL is the arithmetic product of GI and amount of carbohydrate consumed divided by 100 . It describes the overall effects of both quantity and source of carbohydrate on postprandial glycemia [4].

WHO [5] highlighted poor diet as one of the major causes of DM, abnormal lipid profiles and CVDs in addition to other causes like raised blood sugar, physical inactivity, obesity, etc. Thus, what man eats as food for sustenance, growth and development has gradually become a death trap for humanity. Consequently, diets have been considered the first-line of intervention in the prevention, management and treatment of DM and CVDs, and many studies have thus been designed to assess the effect of dietary determinants on their metabolic risk factors [6], such as GI, GL and lipid profiles in humans and experimental animals.

According to Bonora et al. [7], dietary carbohydrate is the main dietary component affecting insulin secretion and postprandial glycemia (PPG), which has been implicated as the cause of several chronic diseases, DM and CVDs inclusive. High GI and GL food intake, as well as, high carbohydrate's intake can cause hyperglycemia 
which is a well-established primary risk factor for DM and CVD. These types of foods would raise blood glucose levels and also plasma fasting triacylglycerol by enhancing hepatic synthesis of very low-density lipoprotein cholesterol (VLDL-C), while reducing high density lipoprotein cholesterol (HDL-C) thus, creating adverse lipid profiles that can increase the risk of having CVDs [2]. According to Capewell et al. [8], high blood cholesterol, triglyceride, LDL-C etc. have been widely considered as modifiable cardio-metabolic risk factors.

This study was therefore embarked upon to "investigate the glycemic index and glycemic load of soy flour fortified whole wheat meal consumed with Crassocephalum biafrae (Worowo) vegetable soup and the lipid profiles of the test human subjects".

\section{Subjects, Materials and Methods}

\section{Experimental subjects}

Eighteen human subjects comprising of male and female students of Adekunle Ajasin University, Akungba-Akoko, Ondo State, Nigeria, whose interest and consent were documented in a written agreement in addition to been verbally expressed, were selected from various departments of the University and used for this study after obtaining ethical permission/clearance from the University's Health Centre (UHC). The World Medical Association (WMA) declaration of Helsinki ethical principles for medical research involving human subjects was duly observed. The eighteen human subjects were randomly divided into two equal groups of nine participants each i.e. (control and test groups of nine human subjects each). Both groups followed the study protocols (rules) without any prejudice to their social and religious status and were confined within the experimental area for the period (hours) of this study on daily basis.

\section{Food stuffs}

Fresh green sample of Crassocephalum biafrae (Worowo) vegetable was purchased at Ibaka-Akungba local market, Ondo State, Nigeria and was identified and authenticated by Dr. O.A. Obembe, a senior lecturer in the department of Plant Science and Biotechnology of Adekunle Ajasin University, Akungba Akoko, Ondo State, while Honey well whole wheat meal and large seeded variety of soy bean (Glycine max), with creamy color were purchased from Bodija market at Ibadan, Oyo State, and were certified hygienic for human consumption.

\section{Preparation of food stuffs}

Edible portions of fresh Crassocephalum biafrae leafy vegetable were separated from its inedible parts, rinsed in clean water, allowed to drain and subsequently shredded into slices of almost equal sizes. Palm oil, clean drinking water with condiments such as onion, pepper (atarodo), known-chicken maggi cubes and table salt were used to cook (steam) the veggie for about $15 \mathrm{~min}$.

Glycine max (soy bean) was processed into soy flour using Omueti and Morton [9] processing method. The soy flour was then used to fortify whole wheat meal using fortification ratio of 1:3 respectively. The quantity of the mixture and whole wheat meal containing $50 \mathrm{~g}$ available carbohydrate was calculated from the proximate analysis result and prepared into their respective solid pastes for consumption with Crassocephalum biafrae soup (CBS) by each of the test human subjects, while $50 \mathrm{~g}$ of DG was dissolved in $100 \mathrm{ml}$ of water for consumption by each of the control subjects.

\section{Proximate composition of foods}

The proximate composition of the food samples; whole wheat meal (WWM), soy flour fortified whole wheat meal (SFFWWM) and soy flour (SF) in their powdered forms were determined using conventional standard methods of analysis of Association of Official Analytical Chemists, AOAC [10].

\section{Feeding of human subjects}

The control human subjects were fed water-dissolved DG on the first day of the experiment, while the test human subjects were fed the test meals; whole wheat meal cum Crassocephalum biafrae soup (WWMCBS) and soy flour fortified whole wheat meal cum Crassocephalum biafrae soup (SFFWWMCBS) on the 1st and 2nd day of the experiment respectively after $12 \mathrm{~h}$ of overnight fasting.

\section{Blood sample collection}

$3 \mathrm{ml}$ of venous blood samples were collected in plain bottles before and 5 hours after meals from each of the human subjects, and the blood samples were processed into sera used for CVD biomarkers assay.

\section{Lipid profiles assay}

Lipid profile parameters such as TC, TG, HDL-C and LDL-C were determined by enzymatic end point method following the manufacturer's instructions in the randox kits, while VLDL-C was calculated using below formula.

\section{VLDL-C=TRIG $/ 5$}

\section{Blood glucose determination}

The pre and postprandial blood glucose, i.e. fasting blood sugar (FBS) and random blood sugar (RBS) of human subjects were determined once before meals and four times after meals respectively for $2 \mathrm{~h}$ at $30 \mathrm{~min}$ intervals using portable glucometer.

\section{Glycemic index determination}

A modified version of Wolever et al. [11] method introduced by Emaleku [12] was employed in determining the meals' GI. Blood glucose concentrations of the human subjects were used to plot blood glucose response curve graphs, which in turn were used to calculate the incremental area under curves (IUACs) of the various meals (foods) by summing up the surface triangles and rectangles traced in the blood glucose response curve graphs (Figure 1).

The IAUCs were then used to determine the GI of each food by dividing IAUC of each test meal by IUAC of the standard meal, multiply by 100 . For example, the GI calculation formula for SFFWWMCBS is presented below.

GI=IUAC of SFFWWMCBS $\div$ IUAC of reference meal $(D G) \times$ $100 \%$. 
Citation: Emaleku SA, Emaleku GO, Omueti OD (2018) Soy Flour Fortification of Whole Wheat Meal Possessed Low Glycemic Index and Glycemic Load and Reduced Cardiovascular Disease Risk Factors. J Cardiovasc Dis Diagn 6: 313. doi:10.4172/2329-9517.1000313

Page 3 of 6

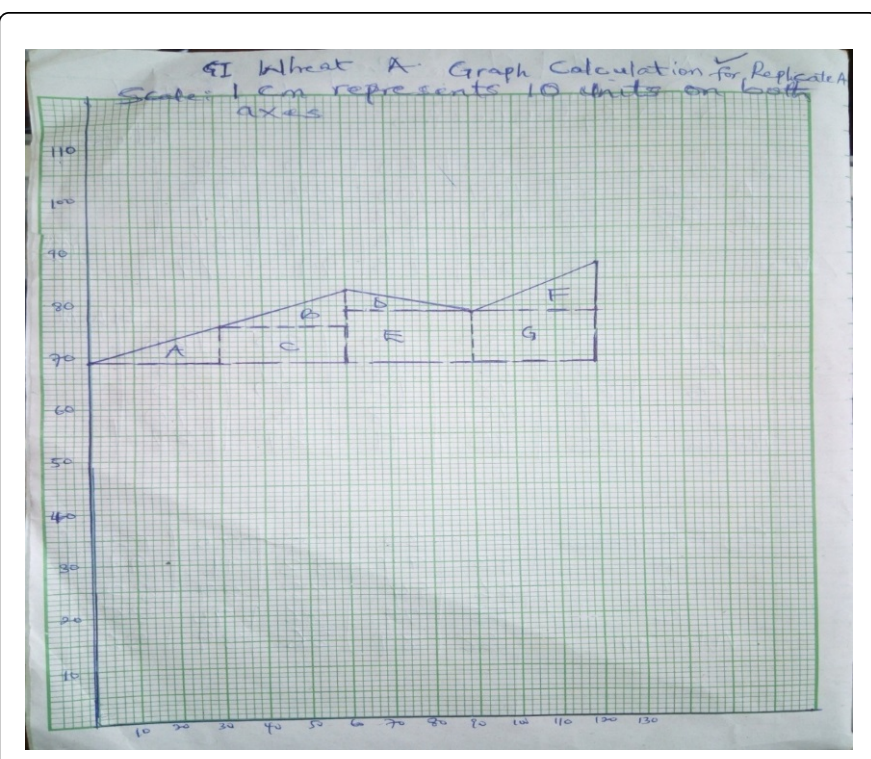

Figure 1: Blood glucose response curve showing how IAUC used for GI determination is being calculated.

\section{Glycemic load determination}

It was calculated by dividing GI of meal by 100 and multiplied by the number (quantity) of available carbohydrate in the meal consumed.

Mathematical representation is as follows: $\mathrm{GL}=\mathrm{GI} / 100 \times$ available carbohydrate $(50 \mathrm{~g})$

\section{Statistical analysis}

CVD biomarkers, GIs and GLs data were statistically analyzed with SAS version 8 software using one-way analysis of variance (ANOVA) with Duncan Multiple Range Test and Pearson Correlation, and results expressed as mean \pm standard error mean (SEM). F-test and T- test at 95 (i.e. 0.05) level of significance was used to assess significant difference. A value of $\mathrm{P}<0.05$ was considered to indicate significant difference between and within groups.

\section{Results}

Table 1 result showed that; SF had the least carbohydrate (10.51\%) and moisture $(7.00 \%)$ contents, but had the highest protein $(50.91 \%)$ and fat $(25.84 \%)$ contents and as well possessed a fairly good fiber (3.27\%) and ash $(2.47 \%)$ contents while, WWM had the highest carbohydrate $(67.73 \%)$ and moisture $(11.20 \%)$ contents, and moderately good protein content (13.86\%), but low (i.e. the lowest) fat (2.87\%) and fiber $(2.61 \%)$ contents. Furthermore, result revealed that; SFFWWM had moderate and improved nutritional contents in comparison with WWM, i.e. above average carbohydrate $(54.88 \%)$, and better protein $(22.83 \%)$, fat (6.28\%), fiber (4.31\%), and ash (1.95\%) contents, but lesser moisture (9.75\%) content.

Table 2 which showed the GI and GL of test meals revealed that SFFWWMCBS had lower GI (28.00\%) and GL (14.00) than WWMCBS's GI (42.67\%) and GL (21.34), although the differences were not significance (Figures 2 and 3). However, both meals' GI and GL were significantly lesser than DG's GI (100.00\%) and GL (50.00) at $(\mathrm{P}<0.05)$.

\begin{tabular}{|l|l|l|l|l|l|l|}
\hline Food Sample & \% Moisture & \% Protein & \% Fat & \% Fiber & \% Ash & \% CHO \\
\hline WWM & 11.20 & 13.86 & 2.87 & 2.61 & 1.73 & 67.73 \\
\hline SFFWWM & 9.75 & 22.83 & 6.28 & 4.31 & 1.95 & 54.88 \\
\hline SF & 7.00 & 50.91 & 25.84 & 3.27 & 2.47 & 10.51 \\
\hline
\end{tabular}

WWM: Whole Wheat Meal; SFFWWM: Soy Flour Fortified Whole Wheat Meal; SF: Soy Flour And CHO-Carbohydrate

Table 1: Food samples proximate composition.

\begin{tabular}{|l|l|l|l|}
\hline Meal Types & GI Values (\%) & GL Values & LSD \\
\hline DG & $100.00 \mathrm{~A} \pm 0.00$ & $50.00 \mathrm{~A} \pm 0.00$ & 23.88 \\
\hline WWMCBS & $42.67 \mathrm{~B} \pm 8.95$ & $21.34 \mathrm{~B} \pm 4.25$ & 23.88 \\
\hline SFFWWMCBS & $28.00 \mathrm{~B} \pm 8.54$ & $14.00 \mathrm{~B} \pm 3.99$ & 23.88 \\
\hline
\end{tabular}

DG: D-Glucose and LSD: Least Significance Difference. Note: Results presented in mean \pm standard error mean $(S E M)$. At $(P<0.05)$, values with the same notations do not differ significantly, but those with different notations do.

Table 2: Glycemic index and glycemic load of meals (foods) consumed.

Figure 4 showed that; SFFWWMCBS caused little spike (increase) in blood glucose levels of subjects and had the least IAUC, while WWMCBS caused moderate blood glucose spike with moderate IAUC, and DG caused inordinate blood glucose spike cum high IAUC.
Considering $30 \mathrm{~min}$ after consumption in Figure 4; SFFWWMCBS increased human blood glucose levels slightly; $91 \mathrm{mg} / \mathrm{dl}-94 \mathrm{mg} / \mathrm{dl}$, while WWMCBS increased it moderately; $87 \mathrm{mg} / \mathrm{dl}-95 \mathrm{mg} / \mathrm{dl}$, and DG increased it greatly; $78 \mathrm{mg} / \mathrm{dl}-122 \mathrm{mg} / \mathrm{dl}$. 
Page 4 of 6

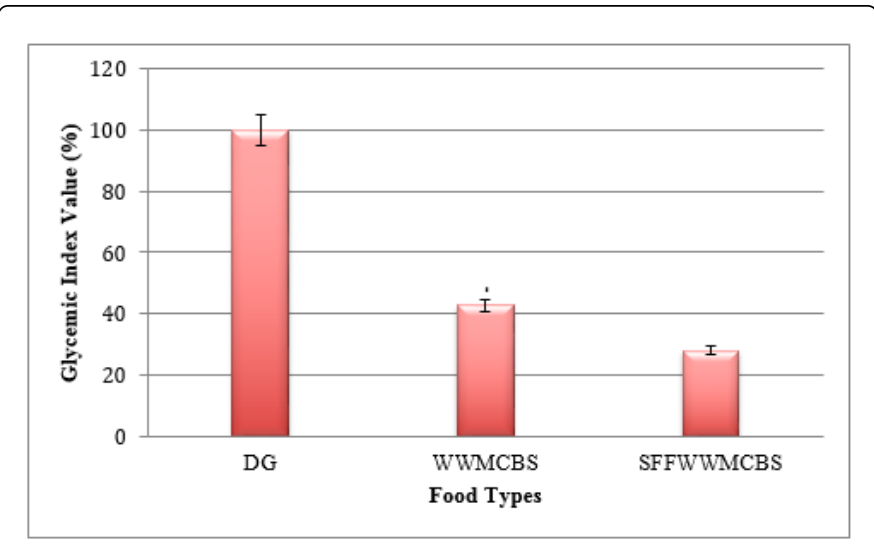

Figure 2: Graphical representation of meals/foods' glycemic index.

Table 3 results showed that, there was no significant difference in TC, TG, LDL-C, VLDL-C and HDL-C concentrations between before meals and after meals at $(\mathrm{P}<0.05)$. Similarly, no significant difference exists in these parameters' concentrations between when the test meals (WWMCBS and SFFWWMCBS) and the control meal (DG) were consumed except in HDL-C at $(\mathrm{P}<0.05)$. However, DG and WWMCBS consumption resulted in high and slight non-significant increase in CVDs risk factors; TC (28.67 and $5.00 \mathrm{mg} / \mathrm{dl}), \mathrm{TG}(17.00$ and $8.00 \mathrm{mg} /$ $\mathrm{dl})$, LDL-C (28.33 and $1.67 \mathrm{mg} / \mathrm{dl})$, and VLDL-C (3.67 and $1.67 \mathrm{mg} / \mathrm{dl})$ respectively at $(\mathrm{P}<0.05)$, while DG decreased HDL-C by $3.00 \mathrm{mg} / \mathrm{dl}$ and WWMCBS minutely increased HDL-C by $0.40 \mathrm{mg} / \mathrm{dl}$. Conversely, SFFWWMCBS non-significantly reduced CVDs risk factors slightly by $0.67 \mathrm{mg} / \mathrm{dl}, 5.67 \mathrm{mg} / \mathrm{dl}, 3.00 \mathrm{mg} / \mathrm{dl}$ and $1.00 \mathrm{mg} / \mathrm{dl}$ for TC, TG, LDL-C and VLDL-C respectively, but increased HDL-C slightly by $2.67 \mathrm{mg} / \mathrm{dl}$.

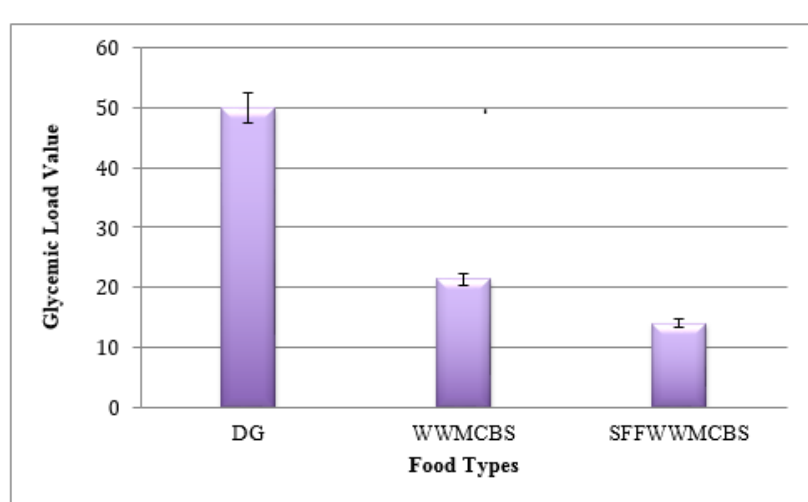

Figure 3: Graphical representation of meals/foods' glycemic load.

Moreover, Table 4 revealed that; CVDs risk factors (TC, TG, LDL-C and VLDL-C) were significantly and positively correlated with one another, but were non-significantly and positively correlated with GI, which in turn was weakly positive and non-significantly correlated with HDL-C like the other CVD risk factors.

\section{Discussion}

Soy flour (SF), a complete protein, is considered equivalent to animal protein in quality and contains all essential amino acids and fiber (both soluble and insoluble) [13]. It is rich in polyunsaturated (linolenic and linoleic acids) and monounsaturated (oleic acid) fatty acids and is also a good source of isoflavones. The mild moist heat treatment of SF during processing tends to help it retain more fats of great biological and therapeutic importance, especially polyunsaturated fatty acids [14] while still possessing good protein content.

According to Emaleku [12], low moist heat (blanching) treatment used in processing this SF might have made it to contain higher unsaturated fatty acids and vitamins B complex, but low protein content when compared with defatted SF that uses high moist heat treatment. Thus, this full-fat or whole soy flour is rich in natural lecithin, a good emulsifier and probably a promoter of good health [15].

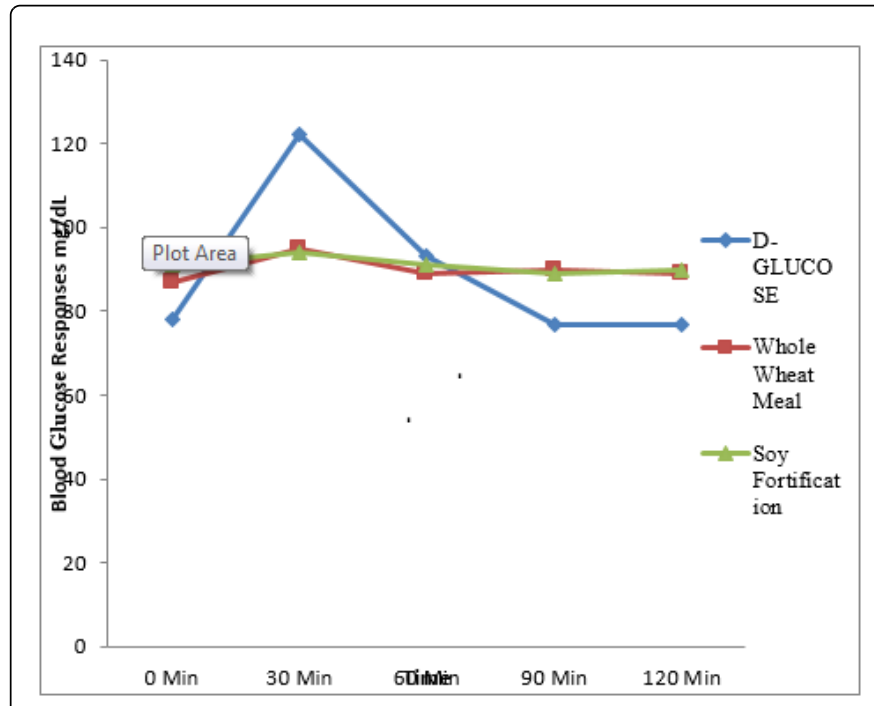

Figure 4: Mean blood glucose response curve of human subjects after meals' consumption.

Therefore, fortification of WWM with SF as in SFFWWM improved its nutritional qualities [16] as shown in Table 1 and would ultimately promote good health in many ramifications as observed in the lipid profile parameters and low GI and GL of SFFWWMCBS. Hence, the nutrients and micronutrients deficiency of WWM was compensated for by the addition of SF.

Isoflavonic phytoestrogens of SF have been consistently found to have hypolipidemic effects and other therapeutic roles [17], which include blood glucose reductions, and the consumption of whole grains like soybean has been consistently linked with a significant decrease in risk factors for CVDs (TC, TG and LDL-C) [18].

For instance, Emaleku et al. [16] reported that soy flour fortification of whole wheat meal consumed with Talinum triangulare soup slightly reduced TC (164.67-163.00 mg/dl), TG (87.67-85.33 mg/dl), LDL-C (68.67-67.33 mg/dl), VLDL-C $(17.67-17.00 \mathrm{mg} / \mathrm{dl})$ by $-1.67 \mathrm{mg} / \mathrm{dl}$, $-2.33 \mathrm{mg} / \mathrm{dl},-1.33 \mathrm{mg} / \mathrm{dl}$ and $-0.67 \mathrm{mg} / \mathrm{dl}$ respectively but, slightly increased HDL-C $(77.33-79.00 \mathrm{mg} / \mathrm{dl})$ by $1.67 \mathrm{mg} / \mathrm{dl}$. Similarly, Anderson et al. [19] also reported that soybean protein consumption resulted in significant reduction of LDL-C and a small but, insignificant increase in HDL-C by $2.4 \%$. And it is important to note that the results of this study as shown in Table 3 are in agreement with the positions of these researchers. 
Citation: Emaleku SA, Emaleku GO, Omueti OD (2018) Soy Flour Fortification of Whole Wheat Meal Possessed Low Glycemic Index and Glycemic Load and Reduced Cardiovascular Disease Risk Factors. J Cardiovasc Dis Diagn 6: 313. doi:10.4172/2329-9517.1000313

Page 5 of 6

\begin{tabular}{|c|c|c|c|c|c|c|c|c|c|c|}
\hline \multirow{2}{*}{$\begin{array}{l}\text { Parameters(mg/d) } \\
\text { Meal Types }\end{array}$} & \multicolumn{2}{|l|}{ TC } & \multicolumn{2}{|l|}{ TG } & \multicolumn{2}{|c|}{ HDL-C } & \multicolumn{2}{|l|}{ LDL-C } & \multicolumn{2}{|c|}{ VLDL-C } \\
\hline & BM & AM & BM & AM & BM & AM & BM & AM & BM & AM \\
\hline DG & $\begin{array}{l}152.0^{\mathrm{A}} \\
\pm 20.0\end{array}$ & $\begin{array}{l}180.0^{A} \\
\pm 25.4\end{array}$ & $\begin{array}{l}90.3^{\mathrm{A}} \quad \pm \\
15.0\end{array}$ & $\begin{array}{l}107.0^{\mathrm{A}} \\
\pm 21.4\end{array}$ & $\begin{array}{l}67.3^{\mathrm{B}} \\
\pm 5.0\end{array}$ & $\begin{array}{l}64.3^{\mathrm{B}} \\
\pm 1.9\end{array}$ & $\begin{array}{l}64.0^{\mathrm{A}} \\
\pm 12.2\end{array}$ & $\begin{array}{l}92.3^{\mathrm{A}} \\
\pm 22.3\end{array}$ & $\begin{array}{l}18.0^{\mathrm{A}} \\
\pm 3.1\end{array}$ & $\begin{array}{l}21.7^{A} \\
\pm 4.4\end{array}$ \\
\hline WWMCBS & $\begin{array}{l}142.7^{A} \\
\pm 16.3\end{array}$ & $\begin{array}{l}147.7^{\mathrm{A}} \\
\pm 18.0\end{array}$ & $\begin{array}{l}81.3^{A} \\
\pm 10.8\end{array}$ & $\begin{array}{l}89.3^{\mathrm{A}} \\
\pm 6.4\end{array}$ & $\begin{array}{l}63.3^{\mathrm{A}} \\
\pm 7.4\end{array}$ & $\begin{array}{l}63.7^{\mathrm{A}} \\
\pm 8.7\end{array}$ & $\begin{array}{l}63.0^{\mathrm{A}} \\
\pm 8.1\end{array}$ & $\begin{array}{l}64.7^{\mathrm{A}} \\
\pm 9.0\end{array}$ & $\begin{array}{l}16.3^{\mathrm{A}} \\
\pm 2.2\end{array}$ & $\begin{array}{l}18.0^{\mathrm{A}} \\
\pm 1.2\end{array}$ \\
\hline SFFWWMCBS & $\begin{array}{l}140.0^{\mathrm{A}} \\
\pm 8.7\end{array}$ & $\begin{array}{l}139.3^{\mathrm{A}} \\
\pm 11.6\end{array}$ & $\begin{array}{l}84.0^{\mathrm{A}} \\
\pm 5.0\end{array}$ & $\begin{array}{l}78.3^{\mathrm{A}} \\
\pm 9.6\end{array}$ & $\begin{array}{l}62.3^{\mathrm{A}} \\
\pm 3.4\end{array}$ & $\begin{array}{l}65.0^{\mathrm{A}} \\
\pm 3.22\end{array}$ & $\begin{array}{l}60.7^{\mathrm{A}} \\
\pm 6.0\end{array}$ & $\begin{array}{l}57.7^{\mathrm{A}} \\
\pm 6.0\end{array}$ & $\begin{array}{l}17.0^{\mathrm{A}} \\
\pm 1.0\end{array}$ & $\begin{array}{l}16.0^{\mathrm{A}} \\
\pm 2.1\end{array}$ \\
\hline LSD & 73.0 & 90.0 & 51.2 & 66.3 & 15.8 & 15.8 & 42.4 & 64.5 & 10.4 & 13.6 \\
\hline
\end{tabular}

BM: Before Meal, AM: After Meal and LSD: Least Significance Difference. Comparison is strictly within the parameters. The results were expressed in Mean \pm SEM with LSD. Values with the same superscript notations do not differ significantly, but those with different superscript notations done at $(P<0.05)$ significance.

Table 3: Effects of meals on human cardiovascular disease biomarkers.

Therefore, the lowered GI and GL values, blood glycemic (postprandial glucose), IAUCs and improved human lipid profiles of SFFWWMCBS to WWMCBS should then be due to the superior protein, fat and fiber contents, and lesser moisture and carbohydrate contents of SFFWWM. According to Henry et al. [20], high fat has the ability to delay gastric emptying, which in turn slow down digestion and absorption of glucose, and thereby prevents eating binge (overeating) that could on long term results to insulin resistance (a metabolic deranged condition) caused by sustained insulin spike. While according to Hätönen et al. [21], high protein level would produce greater gastric inhibitory peptide (GIP); an inhibitory hormone that induces insulin secretion and prompts insulin responses, which would result in lowered postprandial peak and reduced glycemic response due to GIP enhanced insulin activities.

\begin{tabular}{|l|l|l|l|l|l|l|}
\hline Parameters & TC & TG & HDL-C & LDL-C & VLDL-C & GI \\
\hline TC & 1.00000 & $0.91038 S$ & $0.36763 \mathrm{NS}$ & $0.97183 \mathrm{~S}$ & $0.91253 \mathrm{~S}$ & $0.57646 \mathrm{NS}$ \\
\hline TG & $0.91038 \mathrm{~S}$ & 1.00000 & $0.12901 \mathrm{NS}$ & $0.90663 \mathrm{~S}$ & $0.99897 \mathrm{~S}$ & $0.44398 \mathrm{NS}$ \\
\hline HDL-C & $0.36763 \mathrm{NS}$ & $0.12901 \mathrm{NS}$ & 1.00000 & $0.16931 \mathrm{NS}$ & $0.12351 \mathrm{NS}$ & $0.05074 \mathrm{NS}$ \\
\hline LDL-C & $0.97183 \mathrm{~S}$ & $0.90663 \mathrm{~S}$ & $0.16931 \mathrm{NS}$ & 1.00000 & $0.90946 \mathrm{~S}$ & $0.61126 \mathrm{NS}$ \\
\hline VLDL-C & $0.91253 \mathrm{~S}$ & $0.99897 \mathrm{~S}$ & $0.12351 \mathrm{NS}$ & $0.90946 \mathrm{~S}$ & 1.00000 & $0.43597 \mathrm{NS}$ \\
\hline GI & $0.57646 \mathrm{NS}$ & $0.44398 \mathrm{NS}$ & $0.05074 \mathrm{NS}$ & $0.61126 \mathrm{NS}$ & $0.43597 \mathrm{NS}$ & 1.00000 \\
\hline Note: Comparison is strictly within the same parameter. The superscripts S and NS mean differ significantly and no significant difference respectively, at (P<0.05).
\end{tabular}

Table 4: Relationship between cardiovascular disease biomarkers and glycemic index.

Furthermore, high fiber in foods have been reported to have health benefits that include slow glucose absorption, improved insulin sensitivity, reduction in cholesterol and LDL-C levels; as well as reduced incidence of type $2 \mathrm{DM}$, coronary heart diseases, cancers etc [22], and the effects of SFFWWMCBS on blood glucose and lipid profiles (most especially on CVD risk factors) in this research are in agreement with this assertion. Hence, low GI and GL of SFFWWMCBS logically implies that; it would be slowly and gradually metabolized to release blood glucose into the blood stream in a way that would prevent elevated blood glucose, insulin spike and resistance $[23,24], \mathrm{DM}$, and invariably prevent excessive conversion of carbohydrates to fats that might on long term lead to CVDs [16].

Liu et al. [25] observed that GI and GL are inversely associated with HDL-C concentration, but positively associated with triacylglycerol and high-sensitivity C-reactive protein (CRP) concentrations in US women. Evidence from various epidemiological and interventional studies shows that low dietary GI/GL can improve CVD risk factors in Western and Asian adults with or without diabetes [26].

Emaleku et al. [16] reported a non-significant positive association between GI and CVD risk factors, but negative, significant correlation with HDL-C when SFFWWM was consumed with Talinum triangulare soup, and findings of this study still revealed similar trend. This therefore explains why SFFWWMCBS, a lower GI and GL meal than WWMCBS reduced CVD risk factors and improved slightly HDL-C, a cardiovascular benefiting factor better than WWMCBS, while DG, a high GI and GL meal had exactly opposite effects.

\section{Conclusion}

In conclusion, SFFWWMCBS had a lower GI and GL values than WWMCBS and reduced the serum concentrations of the following lipid profile parameters (TC, TG, LDL-C and VLDL-C), but improved HDL-C concentrations. 
Citation: Emaleku SA, Emaleku GO, Omueti OD (2018) Soy Flour Fortification of Whole Wheat Meal Possessed Low Glycemic Index and Glycemic Load and Reduced Cardiovascular Disease Risk Factors. J Cardiovasc Dis Diagn 6: 313. doi:10.4172/2329-9517.1000313

Page 6 of 6

\section{Conflicts of Interest}

There is no conflict of interest among the authors.

\section{Acknowledgements}

We sincerely appreciate God Almighty for His guidance throughout this research period. We also appreciate our institutional colleagues for their unreserved support. We deeply acknowledge the support and cooperation of our families during this study period. God bless you all.

\section{References}

1. World Health Organization (2011) Non-communicable diseases country profiles. WHO global report. http://www. who.int/nmh/publications/ ncd_profiles2011/en/.

2. Ford ES, Zhao G, Li C (2010) Pre-diabetes and the risk for cardiovascular disease: a systematic review of the evidence. J Am Coll Cardiol 55: 1310-1317.

3. Jenkins DJ, Wolever TMS, Collier GR, Ocana AM, Rao AV, et al. (1988) Metabolic effects of a low-glycemic index diet. Am J Clin Nutr 46: 968-975.

4. Brand-Miller JC, Thomas M, Swan V, Ahmad ZI, Petocz P, et al. (2003) Physiological validation of the concept of glycemic load in lean young adults. J Nutr 133: 2728-2732.

5. World Health Organization (2011) Global atlas on cardiovascular disease prevention and control. Non-serial Publications Series 3-18.

6. Reedy J, Krebs-Smith SM, Miller PE, Liese AD, Kahle LL, et al. (2014) Higher diet quality is associated with decreased risk of all-cause cardiovascular disease and cancer mortality among older adults. J Nutr 144: 881-889.

7. Bonora E, Corrao G, Bagnardi V, Ceriello A, Comaschi M, et al. (2006) Prevalence and correlates of postprandial hyperglycemia in a large sample of patients with type 2 diabetes mellitus. Diabetologia 49: 846-854.

8. Capewell S, Ford ES, Croft JB, Critchley JA, Greenlund KJ, et al. (2010) Cardiovascular risk factor trends and potential for reducing coronary heart disease mortality in the United State of America. Bull World Health Org 88: 120-130.

9. Omueti O, Morton O (1996) Development, acceptability, nutritional and physical characteristics of protein improved Nigerian abari (maize meal) prepared from soya and maize flours. Int Journal Food Sci and Nutr 47: 369-375.

10. Association of Official Analytical Chemists (1995) Official methods of analysis 16 th ed. Washington DC, USA; AOAC.
11. Wolever TMS, Jenkins DJA, Jenkins AL, Josse RG (1991) The glycemic index: methodology and clinical implications. Am J Clin Nutr 54: 846 854.

12. Emaleku SA (2013) The glycemic index of soy flour fortified whole wheat meal consumed with Crassocephalum biafrae (worowo) soup and the lipid profile of the test human subjects. B.Sc. Thesis. Adekunle Ajasin University, Akungba-Akoko, Ondo State, Nigeria 45-49.

13. Gupta Y (1987) Nutritive value of soy bean. Int J Tropical Agric 3: 15-23.

14. Henkel J (2000) Soy: Health claims for soy protein, questions about other components. FDA Consumer. 18-20.

15. Ali MB (2002) Characteristics and production cost of US wheat farms. ERS Press, USDA. 974-975.

16. Emaleku SA, Omueti OD, Emaleku GO (2017) Whole wheat meal fortified with soy flour consumed with Talinum triangulare (gbure) soup glycemic index and the test human subjects' lipid profiles. Diabetes \& Metab Synd: Clin Res \& Rev.

17. Zhan S, Ho SC (2005) Meta-analysis of the effects of soy protein containing isoflavones on the lipid profiles. Am J Clin Nutr 81: 397-408.

18. Schwartz R (2007) A whole grain of truth: The authoritative guide to the glycemic index and the dietary solution for lifelong health.

19. Anderson JW, Bryan MD, Johnstone M, Cook-Newell ME (1995) Metaanalysis of the effect of soy protein intake on serum. N Engl J Med 33: 276-282.

20. Henry CJ, Lightowler HJ, Kendall FL, Storey M (2006) The impact of the addition of toppings/fillings on the glycemic response to commonly consumed carbohydrate foods. Eur J Clin Nutr 60: 763-769.

21. Hätönen KA, Virtamo J, Eriksson JG, Sinkko HK, Sundvall JE, et al. (2011) Protein and fat modify the glycemic and insulinaemic responses to a mashed potato-based meal. Br J Nutr 106: 248-253.

22. Turner ND, Lupton JR (2011) Dietary fiber. Adv in Nutr 2: 151-157.

23. Brand-Miller JC, Holt SH, Pawlak DB, McMillan J (2005) Glycemic index and obesity. Am J Clin Nutr 76: 281-285.

24. McKeown NM, Meigs JB, Liu S, Wilson WF, Jacques P (2002) Whole grain intake is favorably associated with metabolic risk factors for type 2 diabetes and cardiovascular disease in the Framingham Offspring Study. 76: 390-398.

25. Liu S, Manson JE, Buring JE, Stampfer MJ, Willett WC, et al. (2002) Relation between a diet with a high glycemic load and plasma concentrations of high-sensitivity C-reactive protein in middle-aged women. Am J Clin Nutr 75: 492-498.

26. Juanola-Falgarona M, Salas-Salvado J, Ibarrola-Jurado N, Rabassa-Solev A, Diaz-Lopez A, et al. (2014) Effect of the glycemic index on weight loss, modulation of satiety, inflammation and other metabolic risk factors: a randomized controlled trial. Am J Clin Nutr 100: 27-35. 